\title{
Nostalgia's Restorative Role at Times of Brand Crisis: An Abstract
}

\author{
Amro Maher, Altaf Merchant, John Ford, and Anusorn Singhapakdi
}

\begin{abstract}
Are consumers likely to forgive a brand during crises, such as Toyota almost a decade ago and recently Wells Fargo? Does nostalgia associated with the brand help alleviate the negativity? What is the role of the consumer's moral makeup? This research addresses the role of managerial response and time in postcrisis recovery. Looking at brand responses to a crisis, it posits that brand nostalgia enhances consumers' forgiveness, assuaging the negative effects of the crises. We argue that brand nostalgia primes long-term orientation and empathy, therefore encouraging consumers to evaluate the crisis from a more distant perspective. We also argue that consumer's moral identity facilitates this process.
\end{abstract}

References Available Upon Request

\footnotetext{
A. Maher

Qatar University, Doha, Qatar

e-mail: amaher@qu.edu.qa
}
A. Merchant $(\bowtie)$
University of Washington Tacoma, Tacoma, WA, USA
e-mail: altafm@uw.edu

J. Ford · A. Singhapakdi

Old Dominion University, Norfolk, VA, USA

e-mail: jbford@odu.edu; asinghap@odu.edu 